\title{
Temas contemporâneos integrados ao currículo de Matemática do Ensino Médio: projeto com o tema
} Arte

\author{
Clarissa de Assis Olgin 1 \\ Claudia Lisete Oliveira Groenwald ${ }^{2}$
}

\section{RESUMO}

Este artigo é um recorte da pesquisa referente à tese de doutorado Temas para o Currículo de Matemática do Ensino Médio que visa contribuir para discussão da seleção de temáticas a serem inseridas no Currículo. O objetivo deste artigo é evidenciar as contribuições do tema Arte, com a utilização do software GeoGebra, na construção e/ou revisão de conceitos matemáticos relativos à Geometria Espacial. A metodologia utilizada baseou-se em uma abordagem qualitativa, na qual se buscou compreender os fenômenos que ocorrem no contexto de sala de aula, quando se trabalha com essa temática. Foi aplicado um experimento com 21 alunos do $1^{\circ}$ ano do Ensino Médio, no município de Caxias do Sul. As análises dos dados coletados apontam que desenvolver atividades com o tema Arte juntamente com recursos computacionais, pode potencializar o processo de ensino e aprendizagem da Matemática, proporcionando ao aluno relacionar o conhecimento matemático com outros assuntos. Neste sentido, considera-se importante buscar/desenvolver atividades didáticas relacionadas a temas que favoreçam o processo de ensino e aprendizagem da Matemática, oportunizando aos estudantes estabelecerem relações entre a teoria e a prática.

PALAVRAS-CHAVE: Currículo de Matemática. Temas de interesse. Arte e Matemática.

\footnotetext{
${ }^{1}$ Doutora em Ensino de Ciências e Matemática. Universidade Luterana do Brasil, Canoas, Rio Grande do Sul, Brasil. http://orcid.org/0000-0001-5560-9276. clarissa_olgin@yahoo.com.br.

2 Doutora em Ciências da Educação. Universidade Luterana do Brasil, Canoas, Rio Grande do Sul, Brasil. http://orcid.org/0000-0001-7345-8205. claudiag1959@yahoo.com.br.
} 
The theme Art: criteria, possibilities and challenges for the development of themes in the Mathematics Curriculum of High School

\begin{abstract}
This article is part of the research regarding the doctoral thesis "Themes for the Mathematics Curriculum of High School" which aims to contribute to the discussion of the selection of themes to be inserted in the Curriculum. The objective of this article is to highlight the contributions of the theme Art, with the use of GeoGebra software, in the construction and /or revision of mathematical concepts related to Spatial Geometry. The methodology used was based on a qualitative approach, in which sought to understand the phenomena that occur in the context of the classroom, when you work with this thematic. An experiment was applied with 21 students from the 1st year of High School, in the municipality of Caxias do Sul. The analyzes of the collected data indicate that to develop activities with the theme Art together with computational resources, may potentiate the teaching and learning process of Mathematics, Providing the student to relate mathematical knowledge with others subjects. In this sense, it is considered important to seek/develop didactic activities related to themes that favor the process of teaching and learning Mathematics, allowing students to establish relationships between theory and practice.
\end{abstract}

KEYWORDS: Mathematics Curriculum. Themes of interest. Art and Mathematics.

El tema Arte: criterios, posibilidades y desafíos para el desarrollo de temas en el plan de estudios de matemáticas de la escuela secundaria

\title{
RESUMEN
}

Este artículo é una sección de la investigación relacionada con la tesis doctoral "Temas para el plan de estudios de matemáticas de la escuela secundaria" que tiene como objetivo contribuir a la discusión de la selección de temas para insertar en el plan de estudios. El objetivo de este artículo es resaltar las contribuciones del tema de Arte, utilizando el 
software GeoGebra, en la construcción y/o revisión de conceptos matemáticos relacionados con la Geometría Espacial. La metodología utilizada se basó en un enfoque cualitativo, que buscaba compreender los fenómenos que ocurren en el contexto del aula, cuando se trabaja con este tema. Se aplicó un experimento con 21 estudiantes del primer año de secundaria, en la ciudad de Caxias do Sul. El análisis de los datos recopilados indican que desarrollar actividades con el tema Arte junto con recursos computacionales, puede mejorar el proceso de enseñanza y aprendizaje de las Matemáticas, proporcionar al estudiante que relacione el conocimiento matemático con otras disciplinas. En este sentido, se considera importante buscar/desarrollar actividades didácticas relacionadas con temas que favorezcan el proceso de enseñanza y aprendizaje de las matemáticas, permitiendo a los estudiantes establecer relaciones entre la teoría y la práctica.

PALABRAS CLAVE: Plan de estudios de matemática. Temas de interés. Arte y Matemáticas.

$$
* * *
$$

\section{Introdução}

Este trabalho é um recorte da pesquisa de doutorado referente a temas de interesse $^{3}$ para o Currículo de Matemática, no Ensino Médio. Está fundamentado em um estudo bibliográfico referente à escolha de critérios para seleção de temáticas nesta etapa da Educação Básica.

Para Olgin e Groenwald (2015) é necessário, nos dias atuais, o desenvolvimento de um currículo que dê significado ao conhecimento escolar e que possibilite formar um estudante capaz de atuar na vida em sociedade.

Salienta-se que os documentos oficiais apresentam uma preocupação com a organização curricular, conforme indicações do Plano Nacional da

\footnotetext{
${ }^{3}$ Temas de interesse são assuntos relevantes para a formação do estudante, sendo temas contemporâneos que possam potencializar o Currículo de Matemática do Ensino Médio, permitindo o desenvolvimento dos conteúdos matemáticos (OLGIN, 2015).
} 
Educação (2011-2020) que expõe a necessidade de diversificar o Currículo do Ensino Médio, buscando estimular o uso de Tecnologias da Informação e Comunicação (TIC), relacionar a educação formal com a popular, incentivar o uso de novas práticas pedagógicas (BRASIL, 2011). Também, no Rio Grande do Sul, na proposta pedagógica para o Ensino Médio Politécnico e Educação Profissional Integrada ao Ensino Médio (2011) que previa a formação de um Ensino Médio politécnico baseado na articulação das áreas de conhecimento e suas tecnologias com os eixos Cultura, Ciência, Tecnologia e Trabalho, no qual buscava que os conteúdos formais tivessem por base os conteúdos sociais.

Já nas indicações da Base Nacional Comum Curricular - BNCC (BRASIL, 2017) no Ensino Médio o foco é a construção de uma visão integrada da Matemática, aplicada à realidade, sendo necessário levar em conta as vivências cotidianas dos estudantes do Ensino Médio, envolvidos, em diferentes graus dados por suas condições socioeconômicas, pelos avanços tecnológicos, pelas exigências do mercado de trabalho, pela potencialidade das mídias sociais, entre outros. Salienta-se, também, duas competências específicas de Matemática e suas tecnologias indicadas pela BNCC (BRASIL, 2017): - utilizar estratégias, conceitos e procedimentos matemáticos para interpretar situações em diversos contextos, sejam atividades cotidianas, sejam fatos das Ciências da Natureza e Humanas, ou ainda questões econômicas ou tecnológicas, divulgados por diferentes meios, de modo a consolidar uma formação científica geral; - articular conhecimentos matemáticos ao propor e/ou participar de ações para investigar desafios do mundo contemporâneo e tomar decisões éticas e socialmente responsáveis, com base na análise de problemas de urgência social, como os voltados a situações de saúde, sustentabilidade, das implicações da tecnologia no mundo do trabalho, entre outros, recorrendo a conceitos, procedimentos e linguagens próprios da Matemática.

Estes documentos enfatizam a necessidade do Currículo de Matemática ser desenvolvido de forma a proporcionar aos alunos uma rede de problemas/situações que possibilitem compreender a realidade econômica, 
social, cultural, política e natural do meio em que vivem. Sendo importante selecionar temas relevantes que façam parte do cotidiano e que viabilizem o desenvolvimento dos conteúdos matemáticos (AZCÁRATE, 1997).

Nesta pesquisa, entende-se que os temas precisam estar relacionados à vida contemporânea e que consigam abarcar os conteúdos matemáticos, identificando as possibilidades e desafios para sua implementação no Currículo de Matemática.

De acordo com os documentos oficiais que norteiam os trabalhos educacionais existe a necessidade de contextualizar os conteúdos matemáticos do Ensino Médio, de forma a propiciar ao estudante o aprender a conhecer, fazer, viver e ser (BRASIL, 1999). Para isso, acredita-se que, desenvolvendo os conteúdos matemáticos através de temas de interesse que envolvam aspectos relevantes da vida em sociedade, os estudantes desta etapa da Educação Básica, conseguirão estabelecer relações entre a teoria e a prática.

A partir do que foi mencionado, o objetivo é evidenciar as contribuições do tema Arte, com a utilização do software GeoGebra, na construção e/ou revisão de conceitos matemáticos relativos à Geometria Espacial. Como sugestão, apresenta-se, neste artigo, atividades organizadas em uma sequência didática, com o tema Arte, para o desenvolvimento de conteúdos matemáticos relativos ao tópico de Geometria Espacial, utilizando na resolução das atividades propostas o software GeoGebra.

\section{Metodologia da Investigação}

A opção metodológica foi de uma abordagem qualitativa, por entender que esta permite que o pesquisador valide os dados através da análise e descrição dos mesmos, visto que, a pesquisa buscou investigar temas de interesse para o Currículo de Matemática, no Ensino Médio, que possibilitem o desenvolvimento dos conteúdos matemáticos, possibilitando aos alunos revisar, aprofundar ou construir novos conceitos matemáticos. 
Primeiramente, foi realizada uma reflexão a partir das pesquisas de Doll Jr. (1997) e Silva (2009), que levaram a elaboração de uma classificação de temas contemporâneos que fossem de interesse para a formação do estudante e que possibilitassem o desenvolvimento de atividades que integrassem os conteúdos matemáticos do Ensino Médio. Em seguida, desenvolveram-se atividades que foram organizadas em uma sequência didática utilizando o tema Arte, levando-se em consideração tais critérios, buscando identificar alternativas didáticas para o professor. Após, realizouse a análise das atividades que foram aplicadas em um grupo de estudantes do Ensino Médio.

\section{Reflexões sobre as contribuições de Doll Jr. e Silva para a seleção de temas no Currículo de Matemática do Ensino Médio}

Ao indicar temas que podem ser desenvolvidos em sala de aula, pretende-se que o currículo seja construtivo, no qual professor e alunos conversem sobre os encaminhamentos da pesquisa, haja a participação ativa dos estudantes nas atividades propostas e que seja possível o desenvolvimento de conceitos matemáticos significativos para a vida do estudante.

Para a construção de critérios para escolha de temas, entende-se que é preciso refletir sobre os quatro "Rs" investigados por Doll Jr. (1997) para avaliar um Currículo Pós-Moderno, que são: riqueza, recursão, relações, rigor.

O critério "riqueza" é identificado pelo autor como um critério que proporciona que professores e alunos transformem e sejam transformados, por meio de atividades integrando temas e conceitos matemáticos, para revisitar ou ampliar os conteúdos já estudados. O critério "recursão" refere-se à possibilidade de escolha de temas que permitam ao aluno refletir-sobre-ofazer, buscando pensar e repensar sobre os caminhos adotados para resolução das atividades. O critério "relações" é importante na escolha de temas, pois evidencia as possíveis conexões entre os temas e os conteúdos matemáticos 
num processo recursivo de fazer, refletindo sobre este fazer. O critério "rigor" está relacionado à escolha de temas que permitam desenvolver os conteúdos matemáticos, buscando conforme as indicações de Silva (2009) verificar as possibilidades metodológicas e organizacionais de aplicação do tema.

Também, os critérios propostos por Silva (2009) (reflexão, realidade, responsabilidade, ressignificação) para escolha e organização dos conteúdos podem ser explorados na seleção de temas para o Currículo de Matemática. Entende-se que os temas a serem desenvolvidos precisam apresentar aspectos relacionados à "reflexão", podendo, através dos temas escolhidos, tratar os conteúdos matemáticos a partir de assuntos relacionados à economia familiar, saneamento básico, entre outros, que também permitem desenvolver problemas locais, o que leva ao critério "realidade" e "responsabilidade", pois verificar possibilidades de solução ou formas de amenizar os impactos de problemas desta natureza, proporcionam aos estudantes perceberem a importância da Matemática na construção da sociedade em que vivem e, o critério "ressignificação" está presente na escolha de temas que desenvolvam os conteúdos matemáticos já estudados em novos contextos.

Os autores Doll Jr. (1997) e Silva (2009) levam à reflexões sobre a construção de atividades que permitam trabalhar os conteúdos matemáticos não apenas buscando o desenvolvimento do conhecimento matemático, mas, também, possibilitando que a Matemática contribua para formação do cidadão, por meio de atividades com temáticas contemporâneas e de interesse para os estudantes.

De acordo com Azcárate (1997), a Matemática poderia ser organizada por uma rede de problemas que permitissem ao aluno compreender e interagir com a realidade social, cultural, política e natural. Mas, para isso é importante identificar quais são os temas que fazem parte da realidade destes alunos e que oportuniza desenvolver conteúdos matemáticos. Desta forma, talvez seja possível uma educação que possibilite o desenvolvimento de estratégias intelectuais que levem a construção de conhecimentos matemáticos que sejam úteis para satisfazer as necessidades da vida pessoal, 
social e profissional dos estudantes.

Portanto, é importante e necessário que se reflita sobre o Currículo de Matemática da Educação Básica, pois são necessárias mudanças para que se tenha um Currículo que proporcione o desenvolvimento dos conteúdos aliados a conhecimentos culturais, sociais e econômicos, favorecendo a formação de um cidadão que saiba atuar de forma crítica/reflexiva na sociedade em que vive.

\section{Classificação dos temas de interesse para o Currículo de Matemática no Ensino Médio}

As reflexões realizadas com a fundamentação teórica contribuíram para a classificação de temas contemporâneos e que fosse de interesse para a formação dos estudantes do Ensino Médio. Identificar temáticas no Ensino Médio visa subsidiar os professores na seleção de assuntos que podem ser desenvolvidos ao longo do Ensino Médio, de forma a propiciar a formação de um sujeito que saiba tomar decisões conscientes na vida em sociedade, valorizando os princípios da democracia e da igualdade para todos.

As temáticas sugeridas nesta pesquisa são um conjunto de assuntos que podem ser utilizados pelos professores para o desenvolvimento dos conteúdos, que possibilitam contemplar uma Educação crítica, transformadora, reflexiva, rica em contextos, permitindo ao estudante envolver-se em cada assunto de forma a revisar, aprofundar, exercitar e estudar os conteúdos desta área do saber.

Entende-se que as temáticas abordadas na Figura 1 podem ser tratadas individualmente, mas também se relacionam, podendo o professor abordar, em sala de aula, uma ou várias temáticas integradas aos conteúdos matemáticos. É importante salientar que a classificação apresentada é uma sugestão, podendo ser ampliada de acordo com os objetivos da escola, o perfil dos estudantes que se pretende formar, a realidade cultural que a escola está inserida. 
FIGURA 1: Temáticas de Interesse para o Currículo de Matemática do Ensino Médio.

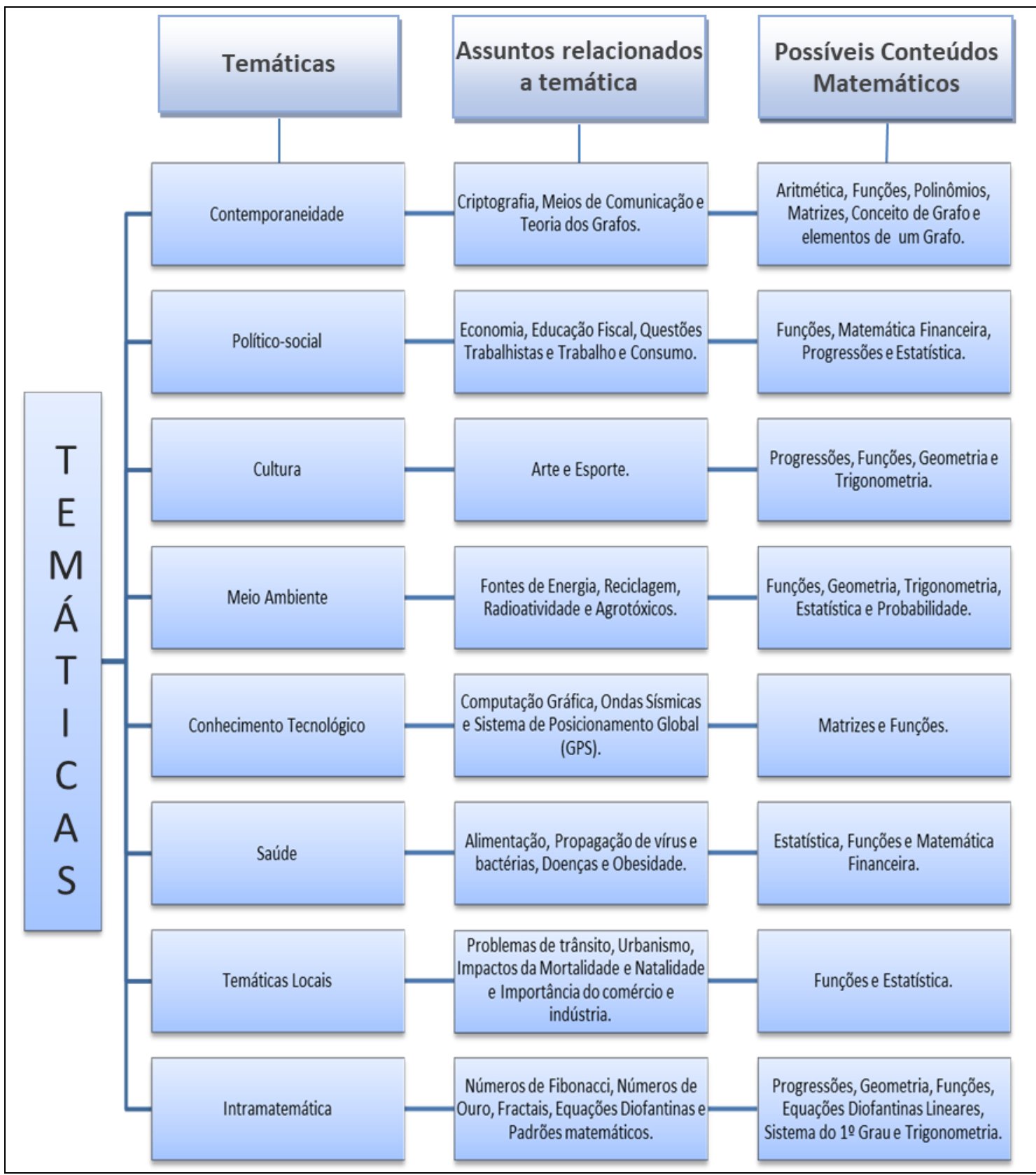

Fonte: adaptado de Olgin (2015).

Neste artigo apresenta-se a temática Cultura, explorando o tema Arte, no Ensino Médio, possibilitando desenvolver assuntos relacionados à arte musical, cênica, visual e ao esporte (Figura 2), considerando-se os aspectos relacionados a cultura e às tradições locais, nas quais os alunos estão inseridos. Esta temática possibilita que o Currículo de Matemática contemple 
os saberes relativos ao contexto sociocultural de cada região.

FIGURA 2: Temática Cultura para o desenvolvimento dos conteúdos matemáticos do Ensino Médio.

\begin{tabular}{|c|c|c|}
\hline TEMÁTICA & TEMAS & $\begin{array}{l}\text { POSSÍVEIS CONTEÚDOS } \\
\text { MATEMÁTICOS }\end{array}$ \\
\hline \multirow[t]{2}{*}{ CULTURA } & Arte & $\begin{array}{l}\text { - Progressões. } \\
\text { - Função Logarítmica. } \\
\text { - Função Exponencial. } \\
\text { - Geometria. }\end{array}$ \\
\hline & Esporte & $\begin{array}{l}\text { - Função Quadrática. } \\
\text { - Trigonometria. }\end{array}$ \\
\hline
\end{tabular}

Fonte: adaptado de Olgin (2015).

De acordo com Marques (2011), o assunto Arte possibilita conhecer a história da construção do pensamento, do conhecimento e do autoconhecimento, pois o homem busca, na Arte, compreender a si, ao outro e ao mundo, por meio da música, pintura, cinema, teatro, poesia, escultura, etc.. Tais manifestações artísticas permitem, por exemplo, a "alfabetização do olhar". Entende-se que o estudante, ao observar uma obra de arte se questiona quanto aos elementos, movimentos, cores, formas e intencionalidade, fazendo uma análise da imagem, para compreender o significado da mesma. Este processo pode desenvolver no aluno o olhar crítico que vai além da observação estética, pois o artista, através de sua arte, expressa um pensamento que é contextualizado no tempo-espaço.

A arte está presente em diversos meios formais e informais, tais como: revistas, jornais, televisão, livros, internet, museus, galerias, teatros, entre outros. Pode auxiliar no trabalho pedagógico, com atividades didáticas que abarquem diferentes culturas, viabilizando diferentes percepções e compreensões do mundo, por meio de assuntos que podem ressignificar os conteúdos matemáticos desenvolvidos em sala de aula, possibilitando o envolvimento dos alunos em uma rede de assuntos que lhes permitam interagir com os conteúdos, mostrando a aplicabilidade dos mesmos na vida em sociedade. 


\section{Arte: uma possibilidade de tema para o desenvolvimento de conteúdos no Currículo de Matemática no Ensino Médio}

A partir das contribuições de Doll Jr. (1997) e Silva (2009), entende-se que pode ser possível desenvolver o tema Arte no Currículo de Matemática do Ensino Médio. De acordo com Silva (2009), um critério para a escolha de conteúdos no Ensino Médio está relacionado à riqueza. Esse critério remete à viabilidade de ajustar os conteúdos às várias práticas existentes no universo escolar. O critério riqueza refere-se à investigação de questões propostas pelo currículo, as quais envolvem conceitos, definições, significados, possibilidades ou interpretações que possibilitem aos alunos e professores se transformar e serem transformados (DOLL JR., 1997). Para isso, o currículo requer um grau de indeterminância, mas, esse fato não deve ser um problema, considerandose que isso ocorre no cotidiano, sendo fundamental para que se tenha um currículo rico e transformador. Isso quer dizer que as inquietações são aspectos próprios do mesmo, os quais lhe dão riqueza. De acordo com Silva (2009), esse critério vislumbra a possibilidade de trabalhar elementos da própria Matemática, buscando mostrar sua diversidade, certezas e incertezas. O critério "riqueza" permitirá que professores e alunos sejam transformados, através de temas que possibilitem desenvolver diversas atividades, construir conceitos, revisar ou ampliar os conteúdos matemáticos.

O segundo critério relações, conforme Silva (2009), baseado nas pesquisas de Doll Jr. (1997), diz respeito a duas dimensões: a pedagógica e a cultural. A primeira discute os elementos que estão relacionados à estrutura interna do currículo e a segunda propõe examinar as características da cultura local, mas essas dimensões não se afastam, bem pelo contrário, elas se complementam. A dimensão pedagógica aborda a questão do tempo no processo de ensino e aprendizagem como tendo um papel secundário, visto que a relação entre o currículo e o tempo precisa ser feita da melhor forma possível, pois o currículo não pode levar em consideração apenas a organização linear dos conteúdos. É preciso que o professor saiba com que 
profundidade precisa abordar os conteúdos que serão trabalhados com seus alunos. A segunda dimensão refere-se à influência da cultura nas relações que permeiam o ambiente escolar. Esse critério é importante na escolha de temas, pois evidencia as possíveis conexões entre os temas e os conteúdos matemáticos num processo recursivo de fazer, refletindo sobre esse fazer. $\mathrm{O}$ critério ressignificação refere-se à recontextualização de um conteúdo em outro tema. Segundo Silva (2009), quando se promovem diferentes contextos para compreensão dos conteúdos matemáticos, pode-se produzir novas interpretações que propiciam aos alunos o estabelecimento de relações significativas.

Neste sentido, entende-se que o tema Arte permite: desenvolver atividades didáticas utilizando os conteúdos matemáticos, já desenvolvidos em sala de aula pelos professores, dentro de um contexto que envolve a influência de diferentes culturas; possibilita recontextualizar um conteúdo dentro de outro tema, podendo produzir novas relações e significados, conforme os critérios riqueza, relações e ressignificação propostos por Doll Jr. (1997) e Silva (2009).

\section{Indicando caminhos com o tema Arte no Ensino Médio}

Apresenta-se um exemplo de uma sequência didática com o tema Arte, explorando o conteúdo de Geometria para revisar ou desenvolver os conteúdos matemáticos, no Ensino Médio. Para ilustrar a prática desenvolvida, escolheu-se apresentar as atividades envolvendo o tópico Cilindro que compõe o conteúdo de Geometria Espacial.

Para construir a sequência didática buscou-se subsídios em livros didáticos e nas questões do Exame Nacional do Ensino Médio (ENEM). Assim, para explorar o tema e os conteúdos de Matemática, desenvolveram-se atividades encadeadas em uma sequência didática adaptadas do livro "Descobrindo Matemática na Arte: atividades para o Ensino Fundamental e Médio”, das autoras Fainguelernt e Ashton Nunes (2011), na qual se propõe 
trabalhar os sólidos de revolução a partir da obra de articulação em metal e movimento por micromotor, de Abraham Palatnik.

$\mathrm{Na}$ Figura 3, apresentam-se as atividades, objetivos e conteúdos desenvolvidos na referida sequência didática.

FIGURA 3: Sequência didática com o tema Arte

\begin{tabular}{|l|l|l|}
\hline \multicolumn{1}{|c|}{ Atividade } & \multicolumn{1}{|c|}{ Objetivo } & \multicolumn{1}{c|}{ Conteúdo } \\
\hline $\begin{array}{l}\text { O artista Abraham } \\
\text { Palatnik }\end{array}$ & Conhecer o artista e suas obras & Cultural \\
\hline $\begin{array}{l}\text { Explorando a obra do } \\
\text { artista }\end{array}$ & $\begin{array}{l}\text { Identificar as figuras geométricas } \\
\text { presentes na obra Objetos } \\
\text { Cinéticos. }\end{array}$ & $\begin{array}{l}\text { Geometria Espacial } \\
\text { (Sólidos de revolução) }\end{array}$ \\
\hline Descobrindo o Cilindro & Explorar os elementos do Cilindro & $\begin{array}{l}\text { Elementos do Cilindro: } \\
\text { Bases; Geratriz; Eixo; } \\
\text { Altura. }\end{array}$ \\
\hline Explorando o Cilindro 1 & $\begin{array}{l}\text { Revisar, aprofundar e/ou reforçar o de um Cilindro: } \\
\text { conteúdo de Cilindro. }\end{array}$ & $\begin{array}{l}\text { Planificação dé } \\
\text { Bases; Superfícies; } \\
\text { Planificação. }\end{array}$ \\
\hline Explorando o Cilindro 2 & $\begin{array}{l}\text { Revisar, aprofundar e/ou reforçar o o } \\
\text { conteúdo de Cilindro. }\end{array}$ & $\begin{array}{l}\text { Secção transversal; Secção } \\
\text { meridiana; Área da } \\
\text { Superfície de um cilindro; } \\
\text { Volume de um cilindro. }\end{array}$ \\
\hline $\begin{array}{l}\text { Atividades de livros } \\
\text { didáticos e do ENEM }\end{array}$ & $\begin{array}{l}\text { Aplicar o conteúdo de Cilindro nas } \\
\text { atividades propostas. }\end{array}$ & \begin{tabular}{l} 
Cilindro \\
\hline
\end{tabular}
\end{tabular}

Fonte: a pesquisa.

Buscou-se nessas atividades o desenvolvimento da Arte Cinética que se caracteriza pela exploração de efeitos visuais através de movimentos físicos ou ilusão de óptica. Por meio das obras do artista Abraham Palatnik pretendeu-se explorar o conteúdo matemático de Geometria Espacial, utilizando diferentes recursos na elaboração das atividades didáticas, tais como, software livre para construção de sólidos de revolução e vídeos do Youtube para conhecer o autor. Também, ao desenvolver as atividades percebeu-se que a calculadora poderia ser utilizada como um recurso facilitador nos cálculos de área e volume dos sólidos.

A sequência didática das atividades propostas foi organizada em seis momentos, conforme se apresenta na Figura 4. 
FIGURA 4: Organização da sequência didática.

\begin{tabular}{|l|l|}
\hline MOMENTOS & \multicolumn{1}{|c|}{ DESCRIÇÃo } \\
\hline $1^{\circ}$ Momento & Apresentação do artista Abraham Palatnik e suas obras. \\
\hline $2^{\circ}$ Momento & Descobrindo conceitos de Geometria Espacial na obra do artista. \\
\hline $3^{\circ}$ Momento & $\begin{array}{l}\text { Utilizando o software GeoGebra para manipulação de sólidos de } \\
\text { revolução. }\end{array}$ \\
\hline $4^{\circ}$ Momento & $\begin{array}{l}\text { Desenvolvendo atividades didáticas com o tema aliado aos conteúdos } \\
\text { matemáticos. }\end{array}$ \\
\hline $5^{\circ}$ Momento & $\begin{array}{l}\text { Desenvolvimento de atividades retiradas ou adaptadas de livros didáticos } \\
\text { e da prova do ENEM envolvendo o tema arte. }\end{array}$ \\
\hline
\end{tabular}

Fonte: a pesquisa.

No momento 1 foi apresentado, em PowerPoint com hiperlink para um vídeo do Youtube, o artista Abraham Palatnik e suas obras, buscando que os alunos conhecessem a biografia do autor e suas principais obras de arte.

No momento 2 (Figura 5) os alunos foram convidados a estudar os sólidos de revolução. Buscou-se que os alunos identificassem quais são os sólidos de revolução e seus elementos.

FIGURA 5: Objeto Cinético.

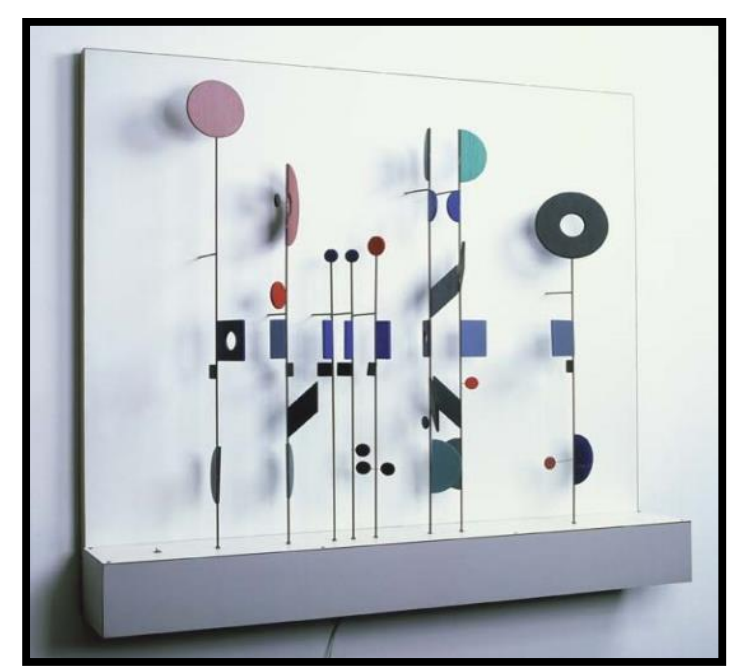

Fonte: retirado de Olgin (2015, p.250).

No momento 3 utilizou-se o software GeoGebra, para manipulação de sólidos de revolução (Figura 6). 
FIGURA 6: Construções de Objeto de Aprendizagem no software GeoGebra.

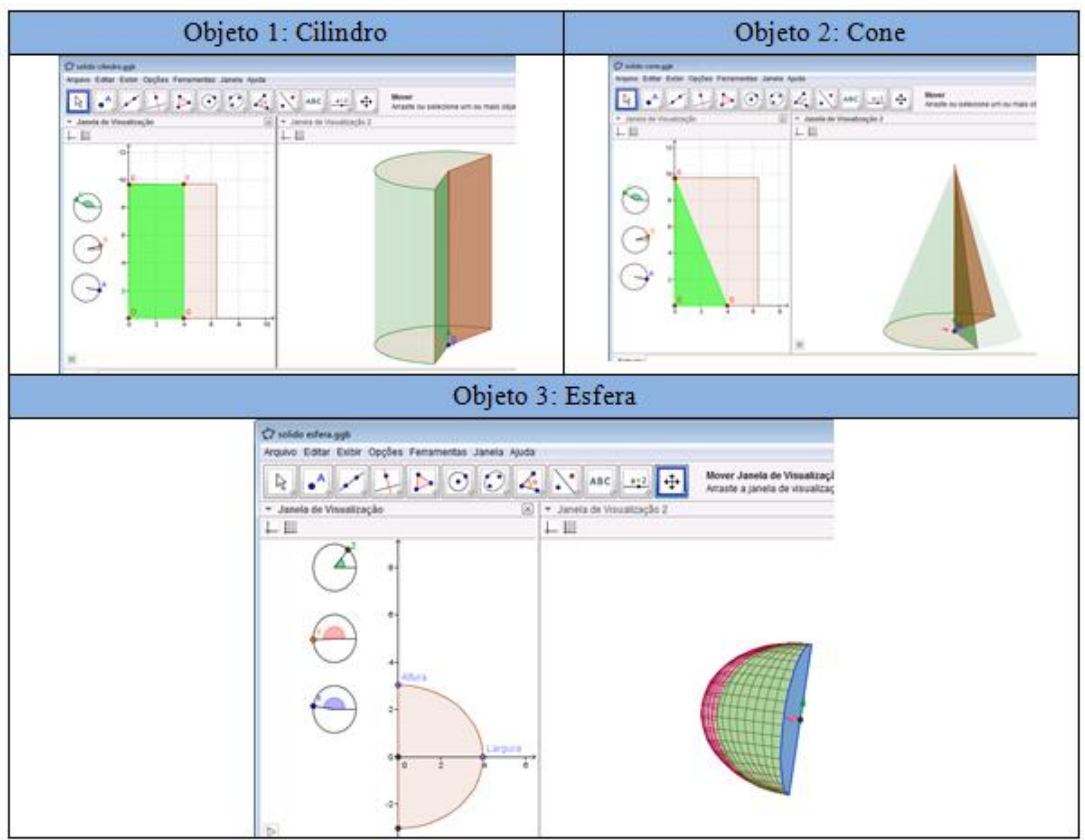

Fonte: a pesquisa.

No momento 4 foram aplicadas atividades didáticas com o tema Arte aliado ao conteúdo matemático Cilindro. A seguir apresentam-se as atividades desenvolvidas.

Atividade 1: Primeiramente solicitou-se aos alunos que a partir do objeto 1 construído no GeoGebra, construíssem um retângulo que tivesse a medida da altura igual a $6 \mathrm{~cm}$ e a medida da base igual a $2 \mathrm{~cm}$, com o software. Após, foi solicitado que realizassem a rotação completa do retângulo, utilizando o comando de animação, que permitiu gerar um cilindro de revolução. Em seguida, propôs-se os seguintes questionamentos: Qual será o raio da base do cilindro obtido? Qual será o diâmetro da base? Qual será a medida da altura do cilindro? Qual será o comprimento da circunferência de cada uma das bases? Qual será a área de cada uma das bases do cilindro obtido?

Atividade 2: Foram realizados questionamentos aos alunos quanto à planificação da superfície lateral do cilindro construído na atividade 1: - Você conseguiria fazer o esboço da planificação do cilindro da atividade 1 e determinar as formas geométricas que podem ser encontradas? - Identifique 
as relações entre as formas geométricas e o cilindro, quanto à medida da altura e da base. Com essas informações, determine a área lateral e a área total do cilindro gerado pela rotação.

Atividade 3: Foram realizadas questões explorando secções de um cilindro, área lateral, área da base, área total e volume (Figura 7).

FIGURA 7: Atividades envolvendo os conteúdos matemáticos.

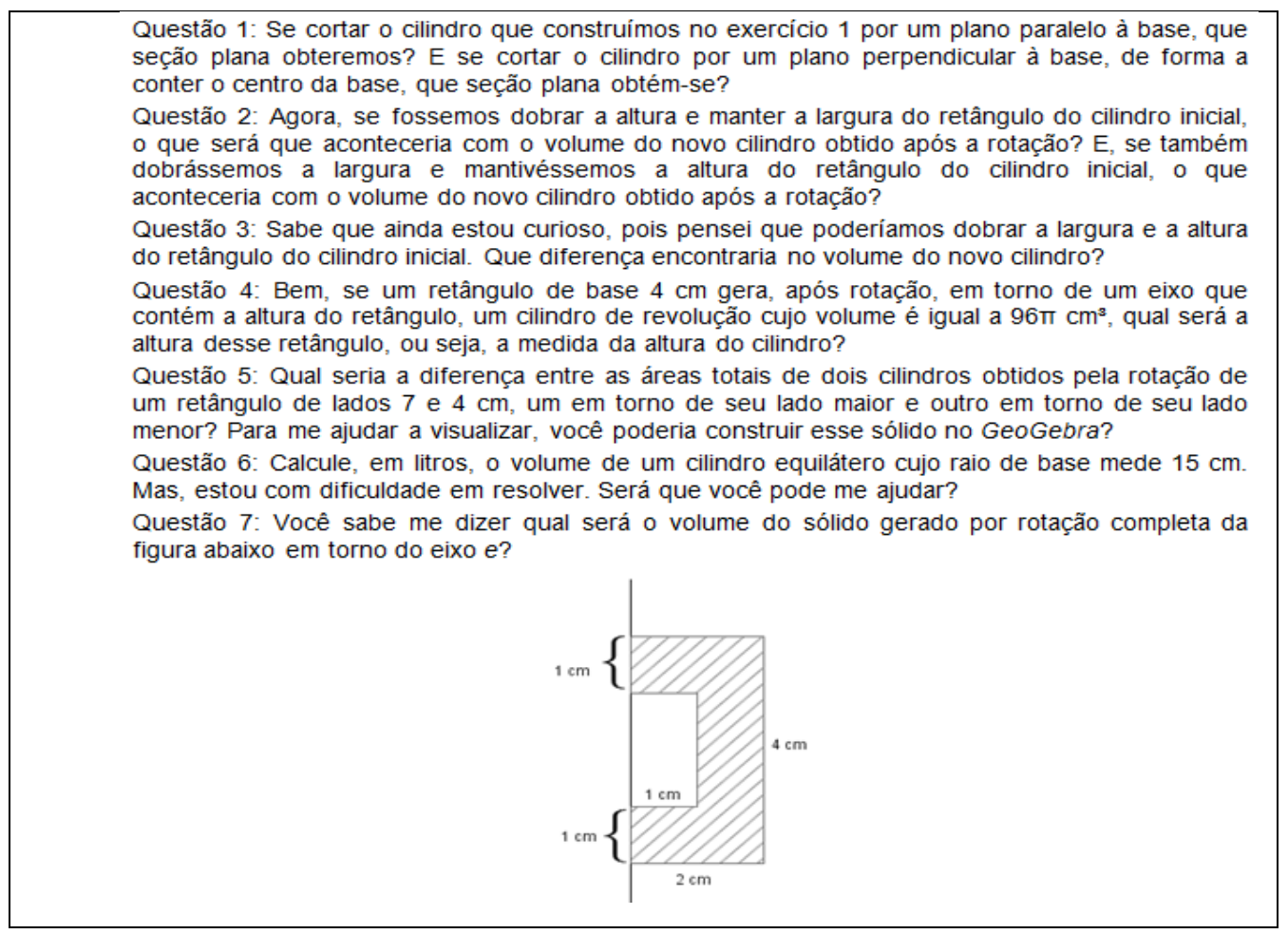

Fonte: retirado de Olgin (2015, p.186-190).

No momento 5 foram desenvolvidas atividades retiradas ou adaptadas de livros didáticos e do ENEM envolvendo o tema arte e o conteúdo em estudo. A seguir apresentam-se as atividades pesquisadas.

Atividade 1: (Retirado de Ribeiro, 2010, p.139) Para obter uma mistura de cor alaranjada, um pintor utiliza-se de uma lata grande, em formato cilíndrico, cuja altura é $30 \mathrm{~cm}$, contendo tinta de cor amarela, e de uma lata pequena, com tinta de cor vermelha, contendo da capacidade da lata maior. A mistura é obtida combinando duas porções de tinta amarela para cada porção de tinta vermelha. $\mathrm{O}$ pintor usa todo o conteúdo da lata menor para compor a 
mistura alaranjada. A quantidade de tinta amarela que restou na lata grande corresponde a uma altura aproximada de: a) $12,86 \mathrm{~cm}$; b) $8,57 \mathrm{~cm}$; c) 21,43 $\mathrm{cm}$; d) $18,14 \mathrm{~cm}$.

Atividade 2: (Retirado de Souza, 2010, p.129) O rebolo cônico é um instrumento musical de percussão cuja forma é de um tronco de cone reto, vazado na base menor e geralmente revestido de couro na base maior. Para confeccionar um instrumento desses, com $50 \mathrm{~cm}$ de altura e raios da base menor e maior medindo, respectivamente, $10 \mathrm{~cm}$ e $15 \mathrm{~cm}$, quantos centímetros quadrados de madeira ou alumínio são necessários para confeccionar sua superfície lateral?

Atividade 3: Observe a obra "Objeto Cinético" (Figura 8), de Abraham Palatnik, 1966.

FIGURA 8: Objeto Cinético.

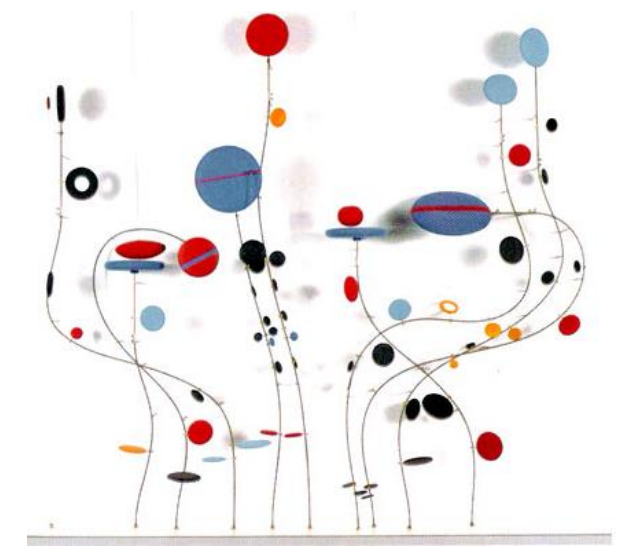

Fonte: retirado de Olgin (2015, p.197).

A arte cinética desenvolveu-se a partir do interesse desse artista plástico pela criação de objetos que se moviam por meio de motores ou outros recursos mecânicos. A obra "Objeto Cinético", do artista plástico brasileiro Abraham Palatnik, pioneiro da arte cinética: a) é uma arte do espaço e da luz. b) muda com o tempo, pois produz movimento. c) capta e dissemina a luz em suas ondulações. d) é assim denominada, pois explora efeitos retinianos. e) explora o quanto a luz pode ser usada para criar movimento. 


\section{Aplicação das Atividades Didáticas envolvendo o tema Arte}

$\mathrm{O}$ experimento foi desenvolvido pelo professor $\mathrm{X} 4$, que atua na rede particular de ensino, nos municípios de Farroupilha e Caxias do Sul.

A investigação foi realizada na escola Impulso ao Saber, do município de Caxias do Sul, do estado do Rio Grande do Sul, com 21 alunos da turma 201, do $1^{\text {o }}$ ano do Ensino Médio, no turno da manhã, em dois períodos a cada dia, totalizando 10 horas aulas.

Para análise da aplicação do experimento aplicado, foram coletados dados durante a fase de experimentação, através das observações do professor da turma, questionários e registros realizados pelos alunos durante o experimento.

Com relação à atividade, na qual se solicitava aos estudantes que elencassem as figuras que observavam na obra de Palatnik, pode-se observar que os alunos não tiveram dúvidas para responder à questão. Mas, percebemse alguns erros de construção de conceitos ou na transposição do conceito para fato, conforme a Figura 9.

FIGURA 9: Exemplo da resolução da atividade.

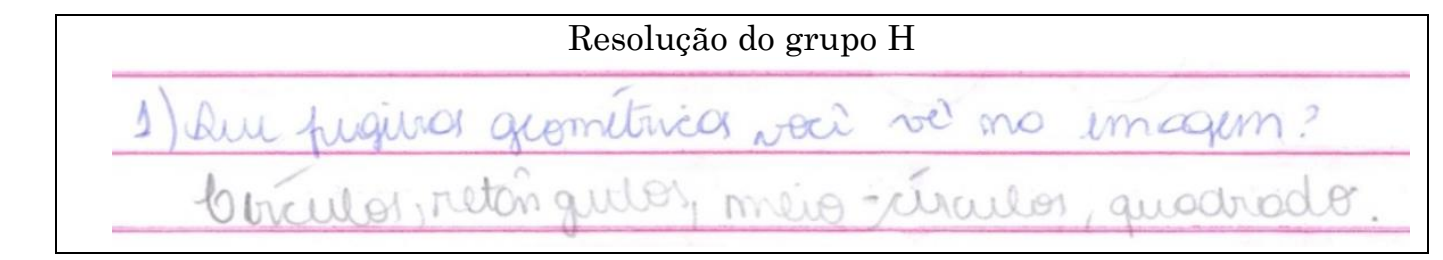

Fonte: a pesquisa.

$\mathrm{Na}$ resposta apresentada pelo grupo $\mathrm{H}$ observa-se que os alunos determinam a figura como meio-círculo, ao invés de semicírculo, a qual representa a forma geométrica representada pela metade de um círculo.

Pode-se perceber, a partir dos dados coletados, que a identificação das formas geométricas, obtida pela rotação de uma figura geométrica em torno

\footnotetext{
${ }^{4}$ A letra "X" é utilizada para representar o nome do professor que aplicou as atividades didáticas desenvolvidas.
} 
de um de seus lados, como, por exemplo, um retângulo, exige dos estudantes uma representação gráfica no papel para determinação da mesma, conforme se observa na Figura 10.

FIGURA 10: Exemplo da resolução da atividade.

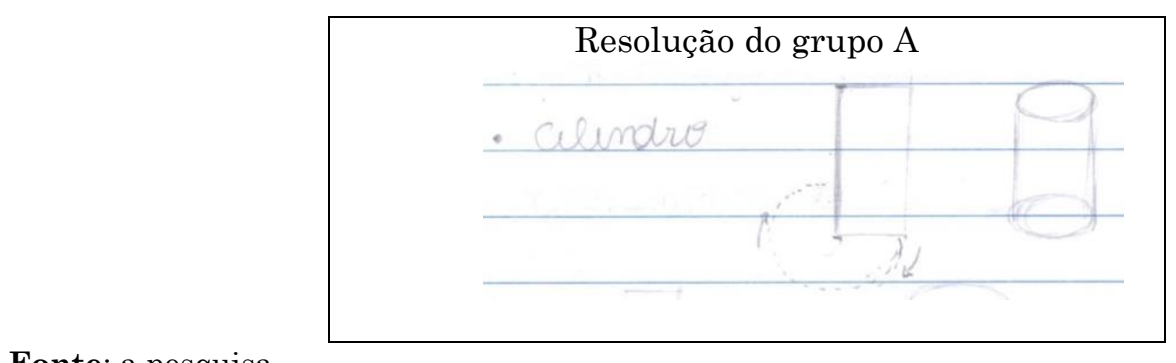

Fonte: a pesquisa.

Percebe-se, ainda, uma confusão ao solicitar que os alunos determinem a forma geométrica obtida ao rotacionar um triângulo retângulo, conforme a resolução apresentada pelo grupo H, na Figura 11.

FIGURA 11: Exemplo da resolução da atividade.

Fonte: a pesquisa.

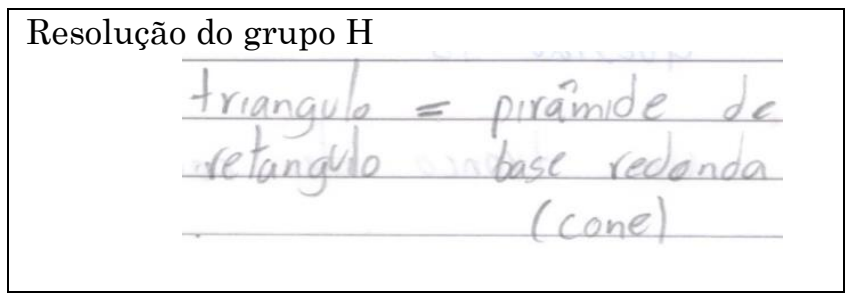

Nessa atividade, é interessante que o professor retome o conceito de pirâmide e explore recursos metodológicos que possam auxiliar o aluno na diferenciação de tais figuras geométricas. Também se percebe que nessa atividade, os alunos apresentaram dificuldades na determinação das formas geométricas encontradas, pois eles confundem círculo e cilindro, como se percebe na resolução apresentada pelo grupo B (Figura 12). Na análise dessa atividade pode-se perceber que os alunos têm dificuldade para estabelecer o nome de uma figura plana e espacial. 
FIGURA 12: Exemplo da resolução da atividade.

Resolução do grupo B
- UM círCUW, cíNDDR NO OASO

Fonte: a pesquisa.

$\mathrm{Na}$ atividade na qual foi solicitado que os alunos planificassem o cilindro, percebeu-se que quatro grupos identificaram as formas geométricas que compõem a figura espacial, ao invés de fazerem a representação da forma geométrica planificada (Figura 13).

FIGURA 13: Exemplo da resolução da atividade.

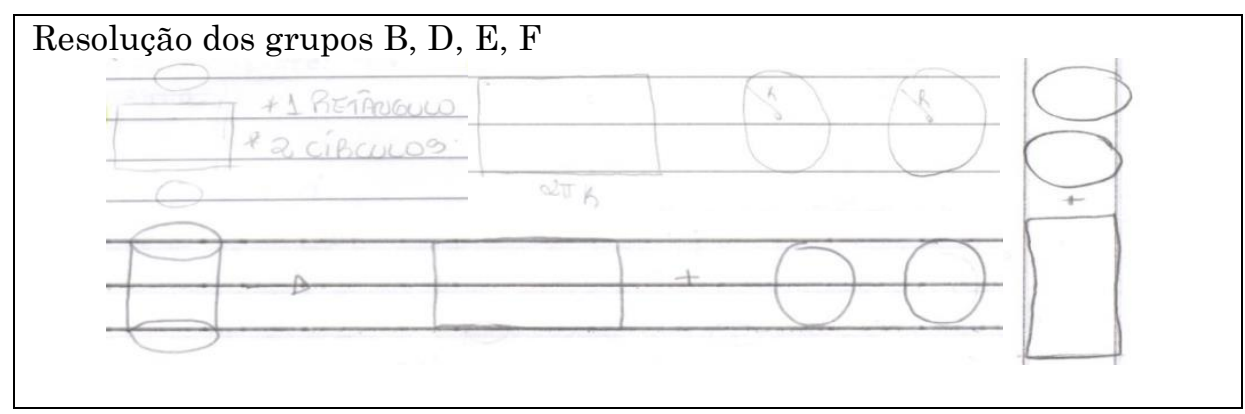

Fonte: a pesquisa.

Com relação à determinação da seção plana obtida ao cortar um cilindro por um plano paralelo e perpendicular à base, os alunos não tiveram dificuldades para determinação da mesma. Mas, é interessante a maneira que o grupo F utilizou para visualizar a seção plana obtida, pois foi necessário fazer a representação no papel dos cortes a serem realizados para estabelecer a seção plana (Figura 14).

FIGURA 14: Exemplo da resolução da atividade.

Fonte: a pesquisa.

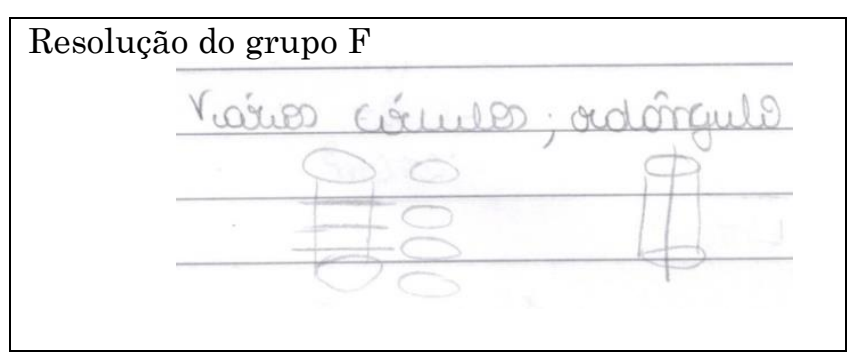


$\mathrm{Na}$ utilização dos conteúdos procedimentais na sequência proposta, como na atividade em que os alunos precisam realizar cálculos para determinação do raio de uma esfera, na qual se tem o valor da área da esfera, percebe-se que eles realizaram os procedimentos de forma adequada para encontrar a solução da atividade (Figura 15).

FIGURA 15: Exemplo da resolução da atividade.

Resolução do grupo H ao lado - Questão: Se tivesse sido construído um semicírculo de raio igual a $5 \mathrm{~cm}$, qual seria o raio da esfera obtida após a rotação completa em torno do eixo $e$ que contém o diâmetro? Mas, e se a área desse semicírculo fosse igual a $8 \Pi \mathrm{cm}^{2}$, qual seria o raio da esfera obtida após rotação completa em torno do eixo e que contém o diâmetro?

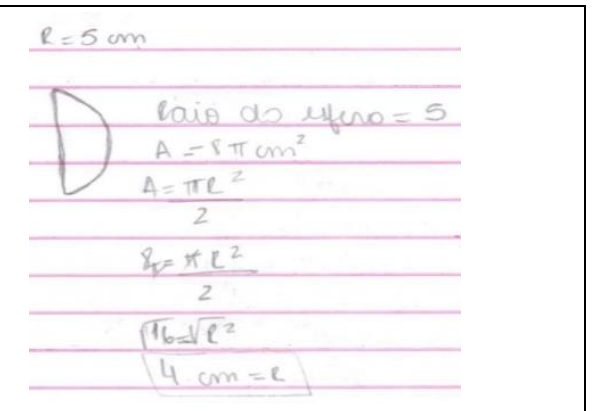

Fonte: a pesquisa.

Este grupo, para a realização da atividade, realizou o levantamento das informações relevantes dadas por ela e aplicou a fórmula para determinar a solução.

Quando se aprofundam as atividades, percebe-se a dificuldade dos alunos, como o grupo $\mathrm{B}$, que acabou não conseguindo chegar à solução da questão, por encontrar dificuldades na manipulação da fórmula com frações (Figura 16).

FIGURA 16: Exemplo da resolução da atividade.

Resolução do grupo B ao lado - Questão: Estive pensando: se o volume de uma esfera A é a oitava parte do volume de uma esfera $B$, qual seria o raio da esfera B, sabendo que o raio da esfera A é igual a $5 \mathrm{~cm}$ ?

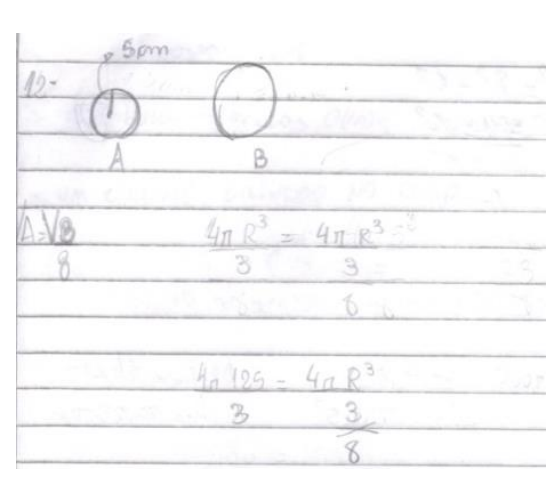

Fonte: a pesquisa. 
Após a intervenção do professor, os alunos do grupo C conseguiram resolver a questão.

As atividades de exploração no software GeoGebra auxiliaram os alunos na visualização das formas geométricas exploradas na sequência proposta com o tema Arte, a partir da obra de Palatnik, bem como permitiram que eles fizessem novas construções, como um circo, um diamante, jarro de suco, pandorga, balde, pudim, forma de bolo, abajur, mapa-múndi, pipa, chapéu de bruxa e vaso, conforme material produzido pelos alunos no software GeoGebra e salvo pelo professor titular da turma (Figura 17).

FIGURA 17: Imagem das produções dos alunos no software GeoGebra.

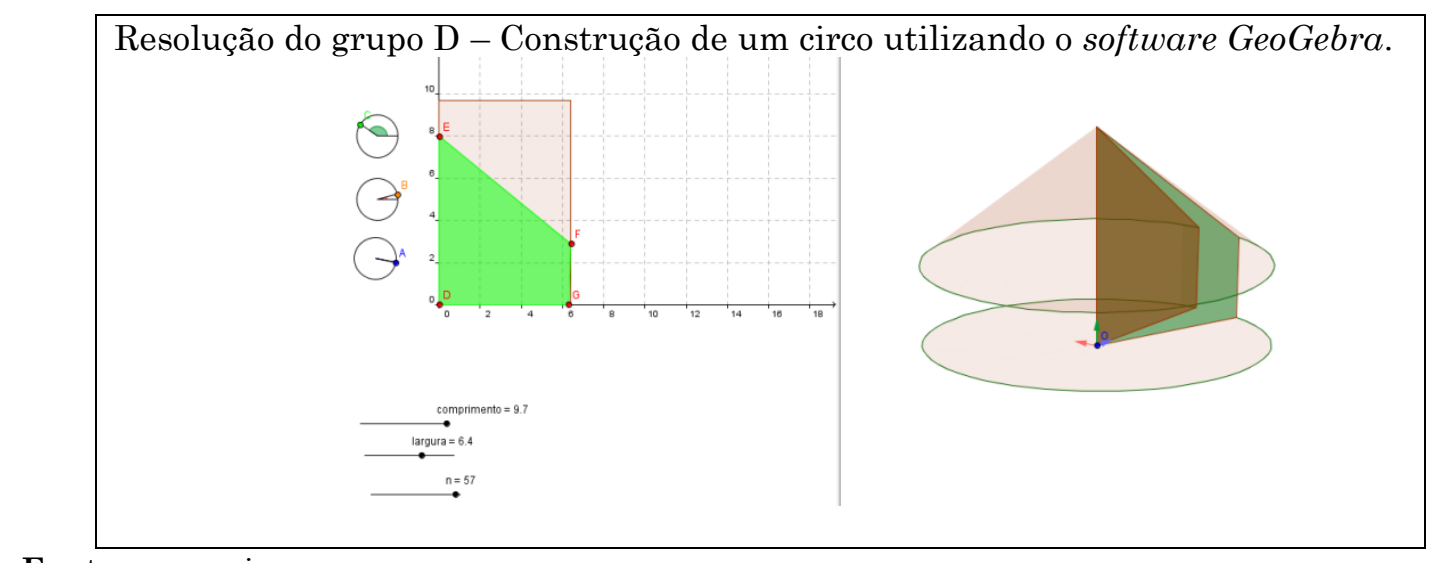

Fonte: a pesquisa.

Percebeu-se, ainda, que as atividades com esse tema abrem a discussão acerca da introdução, em sala de aula, do uso das Tecnologias da Informação e Comunicação, como a utilização do software GeoGebra que, na aplicação do experimento, serviu de facilitador para visualização e manipulação das figuras geométricas abordadas na sequência, que se pode perceber nas imagens coletadas, no instrumento de pesquisa aplicado após a realização do experimento e no material produzido pelos alunos no software em questão (Figura 18). 
FIGURA 18: Dados obtidos com a aplicação do questionário pós-aplicação do experimento.

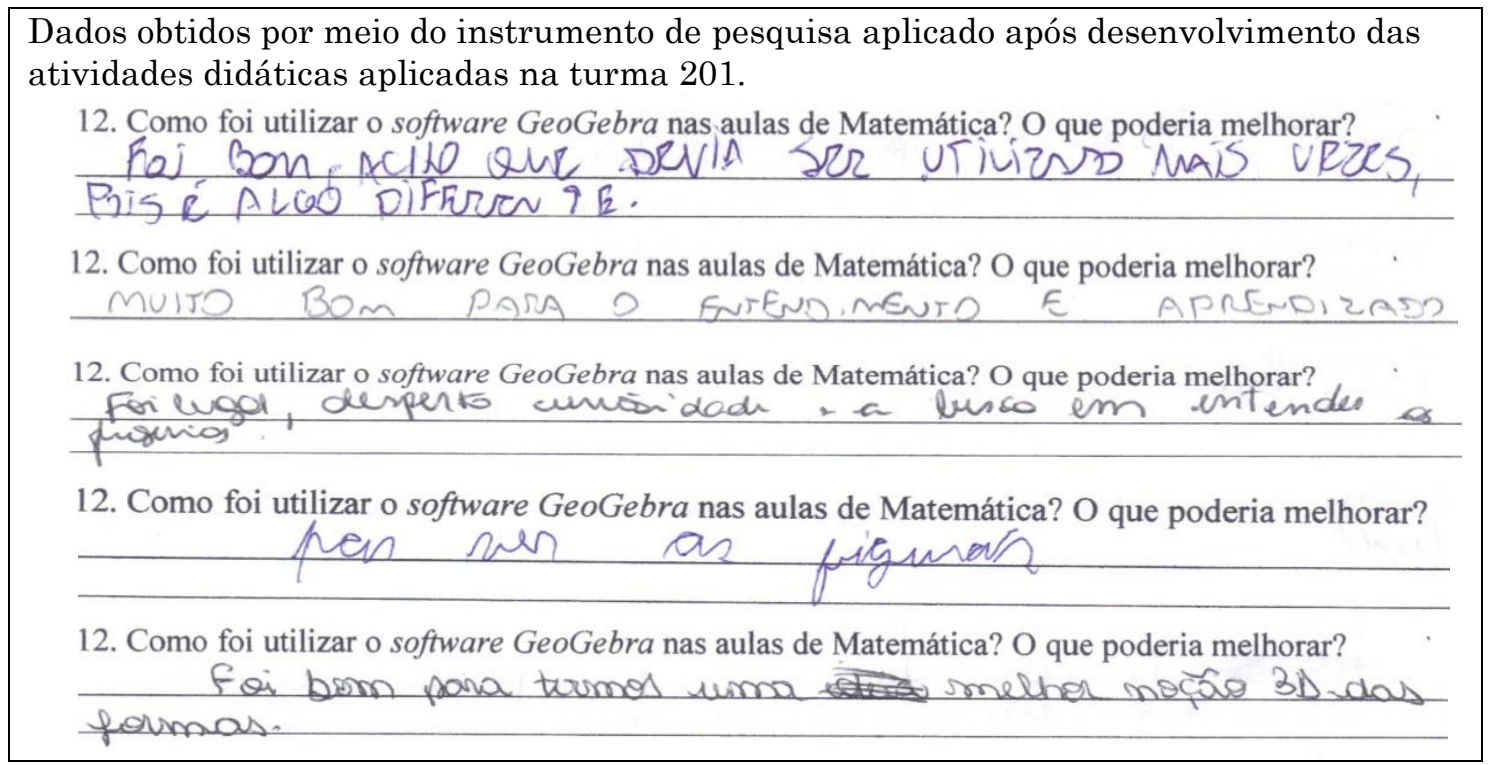

Fonte: a pesquisa.

Ainda com relação a esse item, também foi indicado pelos alunos que poderia haver mais atividades e que as ferramentas do software poderiam ser mais aprofundadas, com aulas específicas sobre como utilizar o software. Esse retorno no questionário, após a aplicação do experimento, mostra o interesse dos alunos no desenvolvimento de atividades com recursos computacionais.

Os resultados indicam que na turma em que foi realizada a aplicação das atividades desenvolvidas, os alunos revisitaram conteúdos estudados anteriormente, ampliando a compreensão dos mesmos, conforme se observou na questão referente à planificação de um Cilindro. As atividades realizadas com os alunos propiciaram o desenvolvimento do critério riqueza, ao permitir aos estudantes trabalharem com o tema Arte e descobrir elementos da Matemática, podendo revisar conceitos que não estavam claros, como, por exemplo, determinar figuras planas e espaciais. Com a mediação do professor durante o processo de aplicação da sequência e a utilização do software GeoGebra. O critério relações foi percebido quando os alunos conseguiram utilizar os objetos matemáticos construídos no software GeoGebra para 
transformação de objetos conhecidos por eles, como, por exemplo, a construção da esfera que se transformou em um Iglu. O critério ressignificação foi verificado na possibilidade de relacionar o tema ao conteúdo de sólidos de revolução, utilizando o recurso do software GeoGebra para visualização das figuras geométricas. Ainda, após a realização das atividades no software GeoGebra, os alunos retornaram às atividades em sala de aula da turma, que envolviam as questões do ENEM e dos livros didáticos de Matemática do Programa Nacional do Livro Didáticos de 2012.

\section{Conclusão}

Entende-se que o tema Arte apresenta potencial para o desenvolvimento de atividades, visto que permite explorar os conteúdos matemáticos relacionados ao tema. Na sequência proposta identifica-se que os conteúdos matemáticos ficaram evidentes, bem como a relação entre os conceitos matemáticos e a Arte. Possibilitou que os alunos conhecessem aspectos referentes à arte cinética, bem como, o percursor desse tipo de arte no Brasil. Viabilizou a manipulação de construções geométricas no software GeoGebra, além de aprimorar os conteúdos abordados na sequência.

Os resultados da aplicação indicam que o trabalho com o tema Arte pode ser viável no Currículo de Matemática do Ensino Médio, no qual o professor pode desenvolver um rol de atividades que permitem o desenvolvimento dos conteúdos matemáticos.

Ressalta-se, também, que o desenvolvimento dos conteúdos matemáticos relacionados a temas, tendo por base as teorias curriculares contemporâneas, pode auxiliar o professor no planejamento de atividades didáticas que busquem potencializar e dar significado a Matemática do Ensino Médio.

\section{Referências}

AZCÁRATE, Pilar. ¿Qué matemáticas necesitamos para comprender el mundo 
actual? Investigación em l Escuela, 32, 77-85, 1997.

BRASIL. Secretaria de Educação Fundamental. Parâmetros Curriculares Nacionais. Introdução aos parâmetros curriculares nacionais. Brasília: Ministério da Educação/ Secretaria de Educação Fundamental, 1999.

BRASIL. Ministério de Educação e Cultura. Base Nacional Comum Curricular Ensino Médio. 2017. Disponível em: http://basenacionalcomum.mec.gov.br/images/historico/BNCC_EnsinoMedio_embai xa_site_110518.pdf.

BRASIL. Projeto de LEI 8035, de 2010. Aprova o Plano Nacional de Educação para o decênio 2011-2020 e dá outras providências. República Federativa do Brasil, Brasília, 2011.

DOLL JR, W. E. Currículo: uma perspectiva pós-moderna. Trad. Maria Adriana Veríssimo Veronese. Porto alegre: Artes Médicas, 1997.

FAINGUELERNT, E. K.; NUNES, K. R. A. Descobrindo matemática na arte: atividades para o ensino fundamental e médio. Porto Alegre: Artmed, 2011.

MARQUES, Rozemeri Pereira. Arte e Educação. Canoas: Editora ULBRA, 2011.

OLGIN, C. A. Critérios, possibilidades e desafios para o desenvolvimento de temáticas no Currículo de Matemática do Ensino Médio. Tese de doutorado, Doutorado em Ensino de Ciências e Matemática, Universidade Luterana do Brasil. Canoas, 2015. Acesso: http://www.ppgecim.ulbra.br/teses/index.php/ppgecim/article/view/214.

OLGIN, C. A.; GROENWALD, C. L. O. Critérios para seleção de temas de interesse para o Currículo de Matemática do Ensino Médio. Perspectivas ea Educação Matemática. 2015, volume 8, número 17. Acesso: https://periodicos.ufms.br/index.php/pedmat/article/view/988.

RIBEIRO, Jackson. Matemática: Ciência, Linguagem e Tecnologia. São Paulo: Scipione, 2010.

RIO GRANDE DO SUL. Secretaria de Estado da Educação. Proposta Pedagógica para o Ensino Médio Politécnico e Educação Profissional Integrada ao Ensino Médio 2011-2014. Novembro 2011.

SILVA, Marcio Antonio da. Currículo de Matemática no Ensino Médio: em busca de critérios para escolha e organização de conteúdos. Tese de doutorado. Pontifícia Universidade Católica de São Paulo, 2009.

SOUZA, Joamir. Novo Olhar Matemática. vol 3. São Paulo: FTD, 2010.

Recebido em janeiro de 2020.

Aprovado em março de 2020. 